\title{
Compatibilidade entre exigências do mercado industrial e desempenho dos alunos de administração
}

Compatibility with industrial requirements and the performance of administration students

\author{
Leonardo Stephanin ${ }^{1 *}$; Jean Felipe Camillo²; Leila Cabana ${ }^{3}$
}

\author{
${ }^{1 *}$ Faculdade Cenecista de Capivari - Graduado em Administração de Empresas - Rua Alemanha, n 90. Bairro: Sto. Antonio. CEP: 13.360-000 - Capivari (SP), Brasil \\ $<$ leo.stephanin@outlook.com> \\ ${ }^{2}$ Faculdade Cenecista de Capivari - Graduado em Administração de Empresas - Rua Laerte Galdino do Nascimento, n 224. Bairro: Santa Rosa. CEP: 13.360-000 - Capivari \\ (SP), Brasil \\ ${ }^{3}$ Faculdade Cenecista de Capivari - Mestre Profissional em Administração - Av. Dois Córregos, n 4205, Apto. H217. Bairro: Nova Iguaçu. CEP: 13.423-100 Piracicaba (SP), \\ Brasil
}

\section{Resumo}

Este estudo teve como objetivo analisar divergências e convergências entre a aprendizagem dos alunos concluintes do curso superior de Administração de uma faculdade privada localizada em Capivari, São Paulo, e as exigências do mercado industrial da cidade. A pesquisa foi desenvolvida em duas etapas, sendo a primeira, uma pesquisa de campo de natureza quantitativa por meio de questionário estruturado com 27 perguntas fechadas e três perguntas abertas, respondido por 13 indústrias, com o intuito de entender as exigências voltadas ao administrador. Posteriormente, foi elaborado um questionário semiestruturado com 35 perguntas fechadas e uma pergunta aberta, respondido por 24 alunos do último ano de Administração a fim de diagnosticar o desempenho em relação aos conteúdos ministrados em sala e indagados às empresas. $\mathrm{Na}$ segunda etapa, por meio de entrevista com o diretor da faculdade estudada, foi diagnosticado o posicionamento da instituição diante do curso e do mercado. Os resultados revelaram que há significativa divergência entre os dois âmbitos, porém temas como as estratégias do mix de marketing e a ferramenta "Customer Relationship Management" [CRM] se destacaram positivamente tanto nas exigências das indústrias quanto no desempenho dos alunos. Do mesmo modo, a ferramenta "Material Requirement Planning" [MRP] e os métodos da localização industrial se sobressaíram em aspecto negativo e também se repetindo nas duas visões.

Palavras-chave: gestão de pessoas, perfil profissional, pesquisa quantitativa, qualificação profissional

\begin{abstract}
This study aimed to analyze divergences and convergences between the learning of undergraduate students of a private Administration course in a college located in Capivari, São Paulo and the industrial market demands of the city. The research was classified as case study and developed in quantitative and qualitative stages. The first stage was conducted through a structured questionnaire with 27 closed and three open questions answered by 13 industries in order to understand the requirements of the administrator. Subsequently, a semi-structured questionnaire with 35 closed and one open ended questions was answered by 24 students in the last year of Administration in order to diagnose the performance in relation to contents given in class and inquired by companies. In the second stage, through an interview with the principal, it was diagnosed the position of the institution before the course and the market. The results revealed that there is a significant divergence between the two scopes, but themes such as the marketing mix strategies and the Customer Relantionship Management [CRM] tool stood out positively both in the industry requirements and in the performance of the students. In the same way, the Materials Requirements Planning $[\mathrm{MRP}]$ tool and the methods of the industrial location excelled in negative aspect and also being repeated in the two visions.
\end{abstract}

Keywords: people management, professional profile, quantitative research, professional qualification

\section{Introdução}

Atualmente o Brasil passa por uma significativa recessão econômica com o Produto Interno Bruto [PIB] retraído e alta taxa de desemprego. Segundo IECONOMICS (2017) 13,2\% da população encontra-se desempregada, o que representa 13 milhões de pessoas à procura de uma fonte de renda, e, conforme o Instituto Brasileiro de Geografia e Estatística [IBGE] (2017) uma taxa de 3,6\% de redução no PIB em 2016, sendo a segunda queda expressiva consecutiva, sendo que no ano anterior houve redução de 3,8\%.

De acordo com Rosa (2013), a população brasileira possui um olhar diferente aos estudos no ensino superior, representando um investimento para a carreira profissional. Também afirmou que para cada ano investido em quaisquer níveis de escolaridade aumentase em média $14 \%$ do salário, e para cada nível de escolaridade superado, estima-se receber $40 \%$ de aumento no nível de renda. 
Muitas empresas consideram como fator primordial o ensino superior de seus empregados, tendo em vista um cenário de grandes avanços tecnológicos, busca pela retenção de bons profissionais e corte de gastos. Souza $(2015)^{1}$ abordou que segundo dados divulgados pelo Instituto Brasileiro de Geografia e Estatística [IBGE], $16 \%$ dos trabalhadores brasileiros possuem ensino superior completo, ao passo que $30 \%$ dos trabalhadores, até final de 2014, não tinham sequer o ensino fundamental concluído, sendo a falta de qualificação profissional um grande problema para as empresas.

É de extrema importância todas as Instituições de Ensino Superior estarem atentas ao currículo apresentado aos estudantes, devendo sempre motivá-los e prepará-los para um emprego promissor. Os professores devem estar compromissados na transmissão de conhecimentos e novas capacitações, como menciona Masetto (2003) que além do professor ter de possuir o diploma de profissional docente também é necessário ter adaptabilidade ao novo, criatividade, autonomia, comunicação, iniciativa e cooperação, e não ser apenas um "professor para ensinar aos que não sabem", e sim, um profissional completo que possua princípios pedagógicos e uma perspectiva político-social.

Para Lakatos e Marconi (2002) a pesquisa científica possui grande importância, pois pretende obter soluções para problemas coletivos, e tem como principal intuito diagnosticar os fatores de uma situação pela qual se deseja estudar, tendo como finalidade encontrar respostas de acordo com o emprego de métodos científicos.

Para a realização da pesquisa foram abordados os principais assuntos que provém da análise ao Projeto Pedagógico de Curso [PPC] $(2014)^{2}$ da faculdade referente ao curso de administração, o qual demonstra todas as ementas em que estão embasados os valores de cada disciplina ministrada, além de seus Planos de Ensino, os quais mencionam os respectivos principais assuntos. Conforme Brasil (2005), que dispõe do artigo $5^{\circ}$ da Resolução n ${ }^{\circ} 4$, de 13 de julho de 2005, os cursos de administração devem atender aos seguintes campos de atuação: Conteúdos de formação básica; conteúdos de formação profissional; conteúdos de estudos quantitativos e suas tecnologias e os de formação complementar.

Neste sentido, este trabalho teve como objetivo analisar divergências e convergências entre a aprendizagem dos alunos concluintes do curso superior de Administração de uma faculdade privada em Capivari, São Paulo, e as exigências do mercado industrial da cidade.
A pesquisa contou com a elaboração de dois questionários e uma entrevista como ferramentas para obtenção dos resultados.

O método empregado na pesquisa foi o estudo de caso. Para a análise dos pontos que se concordam entre a teoria, o desempenho dos alunos de administração e as exigências provindas do mercado industrial local foi utilizada uma pesquisa de campo de natureza quantitativa, mais especificamente um levantamento com dois questionários enviados por e-mail.

O primeiro questionário foi aplicado aos gestores responsáveis pelo setor de contratação de pessoal de cada uma das 22 indústrias, as quais definidas pelo Secretário de Desenvolvimento Urbano da cidade, sendo a ele enviado um pedido para tal atividade como documento formal. Entrou-se em contato por telefone com cada gestor, coletando o e-mail, apresentando os objetivos do trabalho e assegurando os aspectos éticos das informações. Enviou-se o questionário por e-mail nos dias 25 jul. e 26 jul. 2016, com um tempo previsto de resposta por volta de 15 minutos.

Para a primeira parte da pesquisa o questionário online continha 30 questões, sendo 27 perguntas fechadas com diversas opções de resposta (sendo nove delas de múltipla escolha com apenas uma resposta, duas de múltipla escolha com mais de uma resposta e 16 de Escala Likert, que é uma escala linear de avaliação, variando entre 1 e 5, sendo 1 para "Irrelevante", 2 para "Pouco Importante", 3 para "Razoável", 4 para "Muito Importante" e 5 para "Importantíssimo". Apenas uma questão houve também a opção " 0 " como alternativa por não exercer a respectiva atividade) e três questões abertas.

O segundo questionário foi aplicado aos 30 alunos do último semestre do curso, avaliando o desempenho perante os assuntos abordados. Foi apresentada a proposta da pesquisa para os 30 alunos participantes e o questionário foi disponibilizado na sala virtual do site da instituição em que todos os alunos do último semestre do curso superior de Administração teve acesso, no dia 09 ago. 2016. O tempo previsto para responder o questionário foi de 60 minutos.

Para a segunda parte da pesquisa de campo, o questionário online continha 36 questões, sendo todas perguntas fechadas (no caso, 35 delas de múltipla escolha com apenas uma resposta, e apenas uma de escala linear de avaliação, variando entre 1 e 5, sendo 1 para "Nenhum Conhecimento", 2 para "Pouco Conhecimento", 3 para "Razoável", 4 para "Muito Conhecimento " e 5 para "Pleno Conhecimento"), a fim de avaliar o nível de desempenho conquistado em cada uma das principais disciplinas listadas a partir do PPC da faculdade.

\section{Material e Métodos}

\footnotetext{
${ }^{1}$ Souza, B. 2015. Só 16\% dos trabalhadores têm ensino superior completo. Exame. Disponível em: <http://exame.abril.com.br/brasil/so-16-dos-trabalhadores-tem-ensinosuperior-completo/>. Acesso em: 11 abr. 2017.

2 Projeto Pedagógico de Curso. 2014. Projeto Pedagógico do Curso de Administração. Material disponível na intranet. Acesso em: 20 jul. 2016.
} 
Ambos os questionários ficaram disponíveis para responder até o dia 17 ago. 2016, iniciando as tabulações e levantamentos de resultados após esta data.

Por último, a entrevista foi feita com o então diretor, que também foi coordenador e professor da faculdade colhendo informações sobre as propostas e planos para o curso e para a própria instituição. A entrevista ocorreu no dia 23 ago. 2016, discorrendo as respostas para as referidas perguntas.

\section{Resultados e discussão}

Com o questionário enviado aos gestores responsáveis pela contratação direta de cada uma das indústrias, em primeiro plano, percebeu-se que apenas $46,2 \%$ deles ocuparam os três maiores cargos existentes nas empresas (direção, gerência e coordenação), 92,4\% possuem no mínimo o ensino superior completo, 76,9\% com no mínimo dois anos de empresa e $84,6 \%$ com no mínimo dois anos de experiência na função. De forma geral, $53,9 \%$ das indústrias se caracterizaram por possuírem 100 colaboradores ou mais, e 69,2\% de médio ou grande porte.

A aplicação do questionário que se referiu aos alunos concluintes foi realizada a partir do ambiente virtual da faculdade onde todos possuíam acesso. Introdutoriamente percebeu-se que $41,7 \%$ dos alunos teve como objetivo ser apto a trabalhar nos processos administrativos gerais, $37,5 \%$ com o desejo de laborar na área de Gestão de Pessoas, 66,7\% não possuem o conhecimento de uma língua estrangeira, 45,8\% manifestaram interesse em ingressar em uma PósGraduação lato sensu (especialização) e 45,8\% atribuíram "Liderança e Proatividade" como o principal parâmetro de embasamento para alcançar um plano de carreira na organização.

Das 22 indústrias, 13 efetivamente responderam, ou seja, 59,1\%, 3 assinalaram que não poderiam responder por motivos diversos, representando $13,6 \%$, e seis empresas não retornaram, ou seja, 27,3\%. Referente ao segundo questionário, dos 30 alunos, 24 efetivamente responderam, no caso, $80 \%$ e seis não deram retorno, $20 \%$.

A tabela 1 se refere à ordem decrescente dos assuntos listados como mais importantes na visão das indústrias locais. A somatória maior obteve 65 pontos, isso devido à obtenção de 13 empresas respondentes, equivalendo a uma nota 5 .
A tabela 2 se refere à ordem decrescente dos assuntos listados com maior desempenho dos alunos concluintes do curso de Administração da referida faculdade.

Notou-se que há grande discrepância entre o desempenho dos alunos e os graus de importância dados pelas empresas. Também, que há duas questões com aproveitamentos acima de 3,5 na escala adaptada de 1 a 5 para os desempenhos, as quais foram as estratégias do mix de Marketing e a ferramenta CRM, e acima de 2,5, representando mais que $50 \%$ dos alunos, diante dos 33 abordados, houveram-se apenas 10 assuntos. Apenas dois deles obtiveram importância atribuída abaixo de 3,5, os quais foram os conhecimentos do comércio internacional e o cálculo do "mark-up", mostrando que $94 \%$ dos assuntos são classificados como muito importante para as organizações. Três assuntos tiveram aproveitamentos abaixo de $20 \%$, que foram os cálculos de descontos, a ferramenta MRP e os métodos da localização industrial.

A análise da compatibilidade entre os índices quantitativos médios atribuídos pelas empresas e os advindos dos desempenhos dos alunos quanto às habilidades humanas apresentou um índice de mercado de 4,62, sendo o de aluno de 2,92, apresentando um aproveitamento de 58\%. Maximiano (2011) afirmou que as habilidades humanas são as mais importantes e devem ocupar maior proporção na utilização entre as demais.

Quanto às habilidades conceituais o índice quantitativo médio na visão das empresas foi de 4,38, enquanto que no âmbito dos alunos foi de apenas 1,25. $\mathrm{Na}$ visão de Maximiano (2011), complementando com a ideia do assunto anterior, esta habilidade foi importante, porém deve ser utilizada em menor dimensão que a humana, uma vez que a conceitual se refere a funções mais estratégicas, mais específica para o administrador que ocupa o patamar de direção.

Referente ao conhecimento de uma língua estrangeira pelo administrador as empresas demonstraram uma importante exigência quando identificando média de 3,54, se divergindo da realidade encontrada pelos alunos concluintes, dos quais apenas $33,3 \%$ possuem uma segunda língua, com ênfase na língua inglesa, obtendo então índice médio de 1,67. Pedroso (2010) e Periard (2012) enfatizam que o primeiro foco deve ser em relação à língua inglesa, mas possuir fluência em um segundo idioma é essencial para o sucesso não só do administrador como de qualquer profissional do mundo atual. 
Tabela 1. Ranking dos assuntos com maior prioridade ao domínio do administrador conforme a visão das indústrias pesquisadas em ordem decrescente de importância

\begin{tabular}{|c|c|c|c|c|c|}
\hline \multirow[b]{2}{*}{ \# } & \multirow[b]{2}{*}{ ASSUNTOS } & \multicolumn{2}{|c|}{ MERCADO INDUSTRIAL } & \multicolumn{2}{|c|}{ DESEMPENHO ALUNOS } \\
\hline & & $\begin{array}{l}\text { SOMATÓRIA DE } \\
\text { IMPORTÂNCIAS }\end{array}$ & $\begin{array}{c}\text { NOTA } \\
\text { EMPRESAS* }\end{array}$ & $\begin{array}{c}\text { NOTA } \\
\text { ALUNOS** }\end{array}$ & $\%$ \\
\hline 1 & Mapa de Competências & 65 & 5,00 & 2,5 & 50,00 \\
\hline 2 & Habilidades Humanas & 60 & 4,62 & 2,915 & 58,30 \\
\hline 3 & Habilidades Conceituais & 57 & 4,38 & 1,25 & 25,00 \\
\hline 4 & $\begin{array}{l}\text { International Organization of } \\
\text { Standardization [ISO] } 9000\end{array}$ & 57 & 4,38 & 1,25 & 25,00 \\
\hline 5 & Metodologia 5S & 57 & 4,38 & 1,875 & 37,50 \\
\hline 6 & Ferramentas Redes Sociais & 56 & 4,31 & 3,46 & 69,20 \\
\hline 7 & Mix de Marketing & 55,75 & 4,29 & 3,96 & 79,20 \\
\hline 8 & Habilidades Técnicas & 55 & 4,23 & 1,25 & 25,00 \\
\hline 9 & Ciclo Plan, Do, Check, Action [PDCA] & 55 & 4,23 & 1,875 & 37,50 \\
\hline 10 & Rede de Projeto & 55 & 4,23 & 2,29 & 45,80 \\
\hline 11 & Avaliação de Estoque & 54,6 & 4,20 & 1,04 & 20,80 \\
\hline 12 & $\begin{array}{l}\text { Customer Relantionship Management } \\
\text { [CRM] }\end{array}$ & 54 & 4,15 & 3,96 & 79,20 \\
\hline 13 & Pós-Venda & 54 & 4,15 & 2,29 & 45,80 \\
\hline 14 & Planejamento e Controle da Produção [PCP] & 54 & 4,15 & 1,875 & 37,50 \\
\hline 15 & Juros Compostos & 54 & 4,15 & 2,71 & 54,20 \\
\hline 16 & Cálculo de Descontos & 54 & 4,15 & 0,835 & 16,70 \\
\hline 17 & Cálculos Trabalhistas & 54 & 4,15 & 1,665 & 33,30 \\
\hline 18 & Balanço Patrimonial & 53 & 4,08 & 2,915 & 58,30 \\
\hline 19 & $\begin{array}{l}\text { Demonstrativo de Resultado do Exercício } \\
\text { [DRE] }\end{array}$ & 53 & 4,08 & 1,875 & 37,50 \\
\hline 20 & Estratégias Concorrenciais & 52 & 4,00 & 3,335 & 66,70 \\
\hline 21 & Segmentação de Mercado & 52 & 4,00 & 1,875 & 37,50 \\
\hline 22 & $\begin{array}{l}\text { International Organization of } \\
\text { Standardization [ISO] } 14000\end{array}$ & 52 & 4,00 & 1,875 & 37,50 \\
\hline 23 & Sistemas Produtivos & 52 & 4,00 & 1,46 & 29,20 \\
\hline 24 & Feedback & 52 & 4,00 & 3,125 & 62,50 \\
\hline 25 & Ferramentas da Qualidade & 51 & 3,92 & 2,29 & 45,80 \\
\hline 26 & Controle de Estoque & 50 & 3,85 & 2,085 & 41,70 \\
\hline 27 & Materials Requirements Planning [MRP] & 50 & 3,85 & 0,625 & 12,50 \\
\hline 28 & Ferramentas Estratégicas & 49 & 3,77 & 2,915 & 58,30 \\
\hline 29 & Localização Industrial & 47 & 3,62 & 0,625 & 12,50 \\
\hline 30 & Língua Estrangeira & 46 & 3,54 & 1,665 & 33,30 \\
\hline 31 & Formulação de Pesquisas & 46 & 3,54 & 2,085 & 41,70 \\
\hline 32 & Comércio Internacional & 45 & 3,46 & 1,46 & 29,20 \\
\hline 33 & Mark-up & 43 & 3,31 & 2,29 & 45,80 \\
\hline
\end{tabular}

* Refere-se à transposição da somatória das importâncias diante da escala utilizada de 1 a 5; ** A coluna surgiu a partir da coluna “\%”, esta última apresentando o aproveitamento dos alunos, por meio da equivalência à escala usada. Como a escala é de 1 a 5 , possuir um aproveitamento, por exemplo, de 50\%, significa obter uma nota 2,5. Essa foi a transposição realizada no índice referente aos alunos. Fonte: Resultados originais da pesquisa 
Tabela 2. Ranking dos assuntos que obtiveram melhores desempenhos no questionário aplicado aos alunos concluintes da faculdade

\begin{tabular}{|c|c|c|c|c|c|}
\hline \multirow[b]{2}{*}{ \# } & \multirow[b]{2}{*}{ ASSUNTOS } & \multicolumn{2}{|c|}{ MERCADO INDUSTRIAL } & \multicolumn{2}{|c|}{$\begin{array}{l}\text { DESEMPENHO } \\
\text { ALUNOS } \\
\end{array}$} \\
\hline & & $\begin{array}{l}\text { SOMATÓRIA DE } \\
\text { IMPORTÂNCIAS }\end{array}$ & $\begin{array}{c}\text { NOTA } \\
\text { EMPRESAS } \\
\end{array}$ & $\begin{array}{c}\text { NOTA } \\
\text { ALUNOS }\end{array}$ & $\%$ \\
\hline 1 & Mix de Marketing & 55,75 & 4,29 & 3,96 & 79,20 \\
\hline 2 & Customer Relantionship Management [CRM] & 54 & 4,15 & 3,96 & 79,20 \\
\hline 3 & Ferramentas Redes Sociais & 56 & 4,31 & 3,46 & 69,20 \\
\hline 4 & Estratégias Concorrenciais & 52 & 4,00 & 3,335 & 66,70 \\
\hline 5 & Feedback & 52 & 4,00 & 3,125 & 62,50 \\
\hline 6 & Habilidades Humanas & 60 & 4,62 & 2,915 & 58,30 \\
\hline 7 & Balanço Patrimonial & 53 & 4,08 & 2,915 & 58,30 \\
\hline 8 & Ferramentas Estratégicas & 49 & 3,77 & 2,915 & 58,30 \\
\hline 9 & Juros Compostos & 54 & 4,15 & 2,71 & 54,20 \\
\hline 10 & Mapa de Competências & 65 & 5,00 & 2,5 & 50,00 \\
\hline 11 & Rede de Projeto & 55 & 4,23 & 2,29 & 45,80 \\
\hline 12 & Pós-Venda & 54 & 4,15 & 2,29 & 45,80 \\
\hline 13 & Ferramentas da Qualidade & 51 & 3,92 & 2,29 & 45,80 \\
\hline 14 & Mark-up & 43 & 3,31 & 2,29 & 45,80 \\
\hline 15 & Controle de Estoque & 50 & 3,85 & 2,085 & 41,70 \\
\hline 16 & Formulação de Pesquisas & 46 & 3,54 & 2,085 & 41,70 \\
\hline 17 & Metodologia 5S & 57 & 4,38 & 1,875 & 37,50 \\
\hline 18 & Ciclo Plain, Do, Check, Action [PDCA] & 55 & 4,23 & 1,875 & 37,50 \\
\hline 19 & Planejamento e Controle da Produção [PCP] & 54 & 4,15 & 1,875 & 37,50 \\
\hline 20 & $\begin{array}{l}\text { Demonstrativo de Resultado do Exercício } \\
\text { [DRE] }\end{array}$ & 53 & 4,08 & 1,875 & 37,50 \\
\hline 21 & Segmentação de Mercado & 52 & 4,00 & 1,875 & 37,50 \\
\hline 22 & $\begin{array}{l}\text { International Organization of Standardization } \\
\text { [ISO] } 14000\end{array}$ & 52 & 4,00 & 1,875 & 37,50 \\
\hline 23 & Cálculos Trabalhistas & 54 & 4,15 & 1,665 & 33,30 \\
\hline 24 & Língua Estrangeira & 46 & 3,54 & 1,665 & 33,30 \\
\hline 25 & Sistemas Produtivos & 52 & 4,00 & 1,46 & 29,20 \\
\hline 26 & Comércio Internacional & 45 & 3,46 & 1,46 & 29,20 \\
\hline 27 & Habilidades Conceituais & 57 & 4,38 & 1,25 & 25,00 \\
\hline 28 & $\begin{array}{l}\text { International Organization of Standardization } \\
\text { [ISO] } 9000\end{array}$ & 57 & 4,38 & 1,25 & 25,00 \\
\hline 29 & Habilidades Técnicas & 55 & 4,23 & 1,25 & 25,00 \\
\hline 30 & Avaliação de Estoque & 54,6 & 4,20 & 1,04 & 20,80 \\
\hline 31 & Cálculo de Descontos & 54 & 4,15 & 0,835 & 16,70 \\
\hline 32 & Materials Requirements Planning [MRP] & 50 & 3,85 & 0,625 & 12,50 \\
\hline 33 & Localização Industrial & 47 & 3,62 & 0,625 & 12,50 \\
\hline
\end{tabular}

Fonte: Resultados originais da pesquisa

No quesito mix de marketing, o índice implicou positivamente em ambos os âmbitos, pois as empresas atribuíram nível médio de 4,29 e o desempenho dos alunos atingiu índice de 3,96, empatando na primeira colocação do ranking com o CRM, assunto tratado a seguir. Esse patamar positivo enfatizou a importância do assunto dada por Kotler e Keller (2012) e Churchill Jr. e Peter (2012) em estudar o cliente e poder encontrar soluções que sejam eficientes e eficazes ao público-alvo a ser abordado. 
Para o CRM, o índice médio de mercado foi de 4,15 e o índice médio dos alunos foi de 3,96, que como mencionado anteriormente ficou empatado na primeira colocação deste ranking. Destaca-se a importância também enfatizada por Kotler e Keller (2012) e Churchill Jr. e Peter (2012) pelo relacionamento com o cliente, que apesar de o funcionamento geral da empresa não depender deste exclusivamente, se faz como um dos principais "stakeholders" do ambiente de mercado.

Em relação a utilização das ferramentas empresariais das redes sociais o índice representado diante das empresas foi de 4,31, e o desempenho dos alunos foi de 3,46 , aproveitamento de $69,2 \%$, convergindo com a ideia de Senge (2010) que apresentou o grande apoio que o marketing digital oferece às organizações, impulsionando-as para o sucesso antecipadamente e de modo eficiente.

Sobre a avaliação da ferramenta MRP, os índices foram bem divergentes entre os âmbitos, auferindo índice médio de 3,85 na visão das empresas e de apenas 0,63 no conhecimento agregado dos alunos, representando 12,5\% de aproveitamento. Ballou (1993), Longenecker et al. (1997) e Maximiano (2011) enfatizaram a grandíssima importância do conhecimento deste tema, pois afirmaram que se as necessidades dos materiais forem conhecidas podem-se evitar estoques e diversos custos dispendiosos desnecessários, que poderiam ser investidos ou realocados para utilizá-los com maior liquidez.

A análise de compatibilidade entre os âmbitos abordados referente aos métodos da localização industrial mostrou que os resultados não foram dos mais promissores, pois apresentou índice médio de mercado de 3,62 e índice médio acadêmico de 0,63, divergindo Martins e Laugeni (1999) e Slack et al. (2009) no sentido de que o tema apresentou grande importância de haver ciência por parte dos profissionais para utilizarem nas empresas que pretendem se expandir e àquelas que precisam analisar fatores em relação aos seus clientes e fornecedores.

Outro assunto analisado foi em referência aos cálculos simples de descontos que as empresas podem ofertar aos seus clientes, rendendo índice médio relativamente alto de 4,15 no âmbito empresarial, e sob o desempenho dos alunos um aproveitamento de apenas 16,7\%, equivalente a índice de 0,84 na escala Likert. Se resume em conhecimentos básicos matemáticos, como afirma Assaf Neto (2008) e que, por lógica e por exigência léxica do nível do ensino superior, um administrador que teoricamente está preparado para o mercado de trabalho, é mais que seu dever possuir o domínio de ao menos saber o procedimento correto de promover tais cálculos, os quais são ensinados ainda no ensino fundamental.
Quanto ao comércio internacional o índice obtido pelas empresas foi de 3,46, que apesar de ter atingido o patamar de muito importante ocupou a $32^{\mathrm{a}}$ colocação no ranking, e o índice médio no desempenho dos alunos de 1,46, aproveitamento de $29,2 \%$. As definições tratadas por Vazquez (2015) revelam que os conhecimentos foram eficientes para as empresas com interesse em comercializar com o exterior, sendo compatível com as empresas participantes da pesquisa ocupantes deste nicho de atuação.

Possuindo o maior índice médio no ranking de mercado, o assunto denominado de mapa de competências atingiu o nível máximo, 5,00, porém com aproveitamento de $50 \%$ por parte dos alunos, atingindo índice de 2,5. Esta questão aborda assuntos gerais do ramo da Administração por meio da análise criterial e ponderada de um mapa de competências, atribuindo notas e elencando as principais competências e habilidades do profissional de administração.

Apesar de possuir certo foco em Gestão de Pessoas, o qual compreende em analisar as características a partir das habilidades humanas, esta questão realizada aos alunos, retirada e adequada de uma prova do Exame Nacional de Desempenho de Estudantes [ENADE], possui um teor abrangente no que diz respeito em administrar as capabilidades - resumidas em capacidades e habilidades - do recurso mais rico que uma organização pode possuir: as pessoas, como enfatizado por Drucker (2002). Os resultados mostram grande discrepância entre a necessidade de o administrador formado saber aplicar essas ferramentas e a efetividade da prática.

Finalizando a análise detalhada dos principais assuntos destacados na pesquisa, sob as leis que regem os princípios a serem seguidos por determinação da Constituição, autores como Chiavenato (2000) também declararam que o administrador deve ser um profissional com formação ampla, conhecendo diversas disciplinas, capaz de gerenciar pessoas sob todos os níveis hierárquicos, possuir visão holística e influenciar positivamente todos os envolvidos na organização. Witte $(2006)^{3}$ afirmou que o administrador precisa de um perfil, conhecimentos e habilidades únicas sob as rédeas da competitividade do mundo atual. Carvalho (2014) e Maximiano (2011) citaram que os papeis do administrador resumem-se em planejar, organizar, dirigir e controlar e que a capacidade de liderar sobrepõe-se a estas virtudes.

Com as informações apresentadas nas tabelas 1 e 2 , os resultados revelaram que diante dos 33 assuntos passíveis de comparação entre a média de importâncias atribuídas pelas indústrias e o aproveitamento de acertos das questões elaboradas para os alunos, todos os temas foram diagnosticados como no mínimo, importante para o conhecimento do administrador, sendo que na escala Likert, o assunto analisado como menos importante

3 Witte, A. 2006. Contribuições do curso de graduação em Administração para o desenvolvimento pessoal e profissional dos egressos da Universidade Regional de Blumenau - FURB. 2006, 106f. Dissertação (Mestrado em Administração de Negócios) - FURB, Blumenau. 
obteve índice médio de 3,31, evidenciando estar, mesmo assim, acima do "Razoável".

Um ponto a ser analisado com bastante ênfase foi que as duas questões com melhores aproveitamentos no questionário referente aos alunos foram quanto ao mix de Marketing e à ferramenta CRM (ambas com 79,2\%), que compreenderam na gestão do bom relacionamento com os clientes e estratégias de obtenção de informações dos mesmos. Em contrapartida, as duas perguntas que se destacaram por serem as de menor aproveitamento foram referentes à ferramenta MRP, de controle produtivo, e a de localização industrial (ambas com $12,5 \%$ ). Os resultados negativos se convergiram quando analisado no objetivo de atuação por parte dos concluintes do curso, pois nenhum deles escolheu a área de Administração da Produção e Logística.

Também observou que os dois assuntos que se destacaram como os mais importantes, únicos a ultrapassar o índice de " 4,5 ", foram a análise do mapa de competências, o qual englobava diversas aplicações, e a utilização das habilidades humanas pelo administrador. Em contrapartida, os dois temas que se destacaram negativamente, abaixo do índice de " 3,5 ", foram a aplicação do cálculo do "mark-up" e de conhecimentos do comércio internacional.

Dentro da escala utilizada, evidenciando a média geral das importâncias de todos os assuntos tratados na pesquisa e comparando com a média geral do aproveitamento de todas as questões que representaram os respectivos temas, foi diagnosticada certa discrepância entre os resultados, sendo a média geral de 4,07 referente às empresas, havendo assuntos muito importantes, e quanto ao desempenho dos alunos, de 2,11, evidenciando $42,2 \%$ de conhecimento absorvido. Outra observação no desempenho dos alunos foi que apesar de ser abaixo da média geral de acertos, na maioria das questões a resposta que se encontrava correta foi a mais escolhida pelos alunos, diante das demais opções existentes.

Compreendeu-se a tendência da exigência das indústrias de Capivari, São Paulo sobre a área de Marketing, pois a maioria dos assuntos conquistaram posições elevadas no ranking, além de que quando foi perguntado qual o setor mais ocupado por administradores, esta área não obteve resposta, mas ainda assim os resultados desta questão foram passíveis de interpretação sob dois pontos de vista, sendo que o primeiro deles pode apresentar tal tendência de ocupação, e o segundo ponto de vista, a saturação destes profissionais em cada setor. $\mathrm{Na}$ visão dos alunos, apenas $8,3 \%$ dos participantes tiveram a intenção de atuar na área de Marketing, com a maioria disponível para trabalhar em serviços administrativos gerais $(41,7 \%)$ e na área de Gestão de Pessoas (37,5\%).

Os resultados da pergunta realizada a respeito da pósgraduação pretendente dos alunos de Administração revelaram que o foco pela Especialização $(45,8 \%$ ) foi equivalente e concernente à recomendação da maioria das empresas pesquisadas $(53,8 \%)$, visto que de modo geral foi destacado o objetivo central das empresas a optarem pela pós-graduação lato senso que, de acordo com o parecer 977/65 (CAPES, 1965) emitido pelo Conselheiro responsável, esta diretriz tende ao aluno possuir conhecimentos mais pragmáticos, próprios para atender a demanda das atividades organizacionais, enquanto que a pós-graduação do tipo stricto senso possui teor mais acadêmico. Isso sendo logo após o reconhecimento e o desenvolvimento dos cursos de pósgraduação no Brasil, o qual ocorreu a partir de uma lei instaurada em dezembro de 1961 (Giuliani, 2010).

Também referente à visão das empresas, os assuntos menos importantes, em resumo, foram os diversos que destoam das macro áreas de funcionamento de uma organização, sendo eles mais específicos para algumas delas, como o comércio internacional, a formulação de pesquisas, conhecimento de uma língua estrangeira e também o cálculo do "mark-up".

A pesquisa trabalhou com dados e informações referentes aos profissionais de administração com teor principal voltado ao capital humano, considerado por Chiavenato (2010a) como o principal patrimônio existente numa organização e, também concernente à visão de Drucker (2002) que relata que é o recurso mais rico que o administrador pode possuir. Chiavenato (2010b) também confirmou que a avaliação de desempenho é um instrumento muito relevante para medir a eficiência.

Reforçando a ideia do papel das pessoas na organização, Chiavenato (2010a) apresentou as tendências dos embasamentos da definição de carreira, bem como sua aplicação, sendo em uma visão baseada em cargos, ou seja, dada a importância na figura que a pessoa representa diante do cargo ocupado, e em outra, baseada em competências, levando em consideração as virtudes e o desenvolvimento de cada uma delas para que possa exercer o cargo. Em suma, foram visões contraditórias, no sentido de que a primeira perspectiva parte da importância do cargo e vai para a figura do exercício da pessoa, ao passo que o segundo ponto de vista foi antagônico, iniciando da competência profissional e indo ao cargo que tal pessoa possa ocupar.

Em um mundo globalizado e acirrado por inovações e alcances de objetivos, partindo do pressuposto pelos autores que as pessoas foram o capital mais promissor, mais produtivo e mais virtuoso de uma organização, além de visualizar a atribuição de uma média de importância de 4,07 dos assuntos na escala utilizada, é factível que o modelo de gestão e de comportamento profissional atual deve ser de competitividade saudável entre os colaboradores e entre os candidatos a pleitear uma vaga. Senge (2010) enfatizou esse comportamento como motivo à produtividade do colaborador, sempre buscando estar entre os melhores, com ética e respeito, tentando ser o melhor sem rebaixar o próximo. 
Complementando a questão do comportamento do profissional dentro da organização, este índice médio encontrado mostrou que o profissional em administração deve interagir com o que o mercado espera para que possa se especializar e exercer funções que possuam alta demanda e que são vistas com bons olhos. Essa preparação para o mercado de trabalho faz parte do procedimento de construção de um projeto de carreira classificado por Dutra (2002) em seis passos: a autoavaliação, que concederá ao profissional o seu próprio conhecimento, saber suas características intrínsecas que possam ajudá-lo a ter sucesso em determinadas funções; o conhecimento do mercado, evidenciando a relevância da pesquisa; projetar os objetivos de carreira, ou seja, como pretende estar no futuro a curto ou longo prazo; estabelecer as estratégias de carreira, que no caso se resumem nas formas e métodos que utilizará para alcançar os objetivos traçados; também, elaborar um plano de ação, estipulando cenários positivos e negativos conforme as tomadas de decisões; acompanhar tal plano, para que possa avaliar as possibilidades, a eficiência e eficácia do mesmo, e trabalhar sistematicamente em contínua melhoria para que a cada revisão feita, um problema possa ser evitado.

$\mathrm{Na}$ própria pesquisa, há uma questão em que se avaliou qual o principal parâmetro para se ter um plano de carreira tanto na visão das indústrias quanto na visão dos alunos, sendo que apresentou resultado de grande convergência, uma vez que cerca de $80 \%$ dos alunos mencionaram o relacionamento interpessoal, a liderança e a proatividade, e também, segundo as notas atribuídas pelas empresas, como estes os principais aspectos.

\section{Conclusão}

A pesquisa analisa a compatibilidade entre as divergências e convergências entre a aprendizagem dos alunos concluintes de Administração e as exigências do mercado industrial da cidade, e de modo geral, os resultados apontam que as indústrias abordadas podem se assegurar na qualidade da grade curricular utilizada pela faculdade para a formação de administradores, devido à grande compatibilidade encontrada entre o nível de aprendizagem dos alunos e as importâncias atribuídas pelas empresas, sendo que a menor nota gerada na avaliação das organizações está no patamar de "razoável" e muito próxima do "muito importante", equivalente à nota 4 .

A pesquisa evidencia os assuntos com maiores compatibilidades entre as duas visões, sendo com notas altas os referentes à macro área de Marketing (mix de Marketing e CRM) e com notas baixas os concernentes a área da Administração da Produção e Logística (MRP e localização industrial).

Ressalta-se que o trabalho apresenta algumas limitações, como a amostragem de alunos que considerou apenas a turma de formandos daquele ano, sendo que a faculdade já formou outras 40. Além disso, as empresas pesquisadas foram exclusivamente da cidade de Capivari, São Paulo. Como sugestão para futuros trabalhos pode-se considerar outros segmentos como comercio e agropecuária além de outras cidades da região. Outra limitação foi a época inadequada da aplicação dos questionários que coincidiu com a época de pagamentos pelo dos funcionários nas respectivas empresas, pois o contato foi realizado com o gestor ou responsável pelo departamento de Recursos Humanos o que provocou lentidão ou ausência de retorno.

Apesar da exigência das empresas ser baixa quanto aos assuntos de Produção e Logística, os administradores com intenção de atuar nesse ramo precisam de uma preparação mais dinâmica e pragmática ainda na faculdade, podendo então apresentar como sugestões da pesquisa, ter mais disciplinas voltadas à prática do controle produtivo e logístico, ou também, aumentar a carga horária da disciplina de Jogos de Empresas, a qual simula o real funcionamento de uma organização produtiva.

Alinhado a uma das respostas do então diretor quanto ao objetivo da faculdade, que seria de propiciar ao aluno desenvolver autonomia e criticidade, concomitante, e ao mesmo tempo, independente do conteúdo ministrado em sala, a contribuição da pesquisa pode possuir conteúdo político-social, buscando a sinergia entre a sociedade, academia e mercado, e, ainda que desenvolvida em apenas uma cidade, é capaz de contribuir e estimular o desenvolvimento micro e macroeconômico da nação.

\section{Referências}

Assaf Neto, A. 2008. Finanças corporativas e valor. 3ed. Atlas, São Paulo, SP, Brasil.

Ballou, R.H. 1993. Logística empresarial: transportes, administração de materiais e distribuição física. Atlas, São Paulo, SP, Brasil.

Brasil. 2005. Lei Resolução no 4 de 13 de Julho de 2005. Institui as Diretrizes Curriculares Nacionais do curso de graduação em Administração, bacharelado, e dá outras providências. Diário Oficial da União, Brasília, DF, 19 de Julho de 2005, Seção 1, p. 26. Disponível em:

<http://portal.mec.gov.br/cne/arquivos/pdf/rces00 4_05.pdf>. Acesso em: 25 jul. 2016.

Carvalho, C. 2014. Qual o perfil ideal para um bom administrador? Administradores. Disponível em: <http://www.administradores.com.br/artigos/carreir a/qual-o-perfil-ideal-para-um-bomadministrador/79388/> Acesso em: 05 maio 2016.

Chiavenato, I. 2000. Introdução à teoria geral de administração: edição Compacta. 2ed. Campus, Rio de Janeiro, RJ, Brasil.

Chiavenato, I. 2010a. Gestão de Pessoas: o novo papel dos Recursos Humanos nas organizações. 3ed. Elsevier, Rio de Janeiro, RJ, Brasil. 
Chiavenato, I. 2010b. Iniciação à Administração de Recursos Humanos. 4ed. Manole, Barueri, SP, Brasil. Churchill Junior, G.A.; Peter, J. P. 2012. Marketing: criando valor para os clientes. 3ed. Saraiva, São Paulo, SP, Brasil.

Coordenação de Aperfeiçoamento de Pessoal de Nível Superior [CAPES]. 1965. Definição dos Cursos de Pós-Graduação. Disponível em:

<https://www.capes.gov.br/images/stories/downloa d/legislacao/Parecer_CESU_977_1965.doc.>. Acesso em: 27 jul. 2016.

Drucker. P.F. 2002. Introdução à Administração. Pioneira Thomson, São Paulo, SP, Brasil.

Dutra, J.S. 2002. A Gestão de Carreira. p. 99-114. In: Fleury, M.T.L. As Pessoas na Organização. 11ed. Editora Gente, São Paulo, SP, Brasil.

Giuliani, A.C. 2010. Perfil profissiográfico dos egressos do programa de Mestrado Profissional em Administração de uma instituição de ensino do interior do Estado de São Paulo. Rev. Adm. UFSM 3(1): 94-108. Disponível em: <https://periodicos.ufsm.br/reaufsm/article/view/2 242/1369>. Acesso em: 25 jul. 2016.

IECONOMICS. 2017. Brasil: taxa de desemprego. Disponível em: <http://pt.tradingeconomics.com/brazil/unemploy ment-rate>. Acesso em: 11 abr. 2017.

Instituto Brasileiro de Geografia e Estatística [IBGE]. 2017. Indicadores IBGE: contas nacionais trimestrais. Disponível em:

<ftp://ftp.ibge.gov.br/Contas_Nacionais/Contas_N acionais_Trimestrais/Fasciculo_Indicadores_IBGE/p ib-vol-val_201701caderno.pdf $>$. Acesso em: 11 abr. 2017.
Kotler, P. Keller, K.L. 2012. Administração de Marketing. 14ed. Pearson Education do Brasil, São Paulo, SP, Brasil.

Lakatos, E.M.; Marconi, M.A. 2002. Técnicas de Pesquisa. 5ed. Atlas, São Paulo, SP, Brasil.

Longenecker, J.G.; Moore, C.W.; Petty, J W. 1997. Administração de pequenas empresas: ênfase na gerência empresarial. Pearson Education do Brasil, São Paulo, SP, Brasil.

Martins, P.G.; Laugeni, F.P. 1999. Administração da Produção. Saraiva, São Paulo, SP, Brasil.

Masetto, M.T. 2003. Competência Pedagógica do Professor Universitário. Editora Sammus Editorial, São Paulo, SP, Brasil.

Maximiano, A.C.A. 2011. Teoria Geral da Administração: da revolução urbana à revolução digital. Ged. Atlas, São Paulo, SP, Brasil.

Rosa, L. 2013. A formação no ensino superior e o mercado de trabalho. Administradores. Disponível em:

$<$ http://www.administradores.com.br/artigos/carreir a/a-formacao-no-ensino-superior-e-o-mercado-detrabalho/68762/>. Acesso em: 11 abr. 2017.

Senge, P.M. 2010. A Quinta Disciplina: arte e prática da organização que aprende. 26ed. Best Seller, Rio de Janeiro, RJ, Brasil.

Slack, N.; Chambers, S.; Johnston, R. 2009. Administração da produção. 3ed. Atlas, São Paulo, $\mathrm{SP}$, Brasil.

Vazquez, J.L. 2015. Comércio exterior brasileiro. 11ed. Atlas, São Paulo, SP, Brasil. 